\title{
The chemical-in-plug bacterial chemotaxis assay is prone to false positive responses
}

\author{
Jun Li $i^{2}$, Alvin C Go ${ }^{1}$, Mandy J Ward ${ }^{2,3^{*}}$, Karen M Ottemann ${ }^{1,3^{*}}$
}

\begin{abstract}
Background: Chemical-in-plug assays are commonly used to study bacterial chemotaxis, sometimes in the absence of stringent controls.

Results: We report that non-chemotactic and non-motile mutants in two distinct bacterial species (Shewanella oneidensis and Helicobacter pylori) show apparent zones of accumulation or clearing around test plugs containing potential attractants or repellents, respectively.

Conclusions: Our results suggest that the chemical-in-plug assay should be used with caution, that non-motile or non-chemotactic mutants should be employed as controls, and that results should be confirmed with other types of assays.
\end{abstract}

\section{Background}

Numerous spatial assays, described below, are used to monitor bacterial chemotaxis to particular chemicals. In these assays, motile bacteria are first placed in a solution that does not contain the test chemical to be analyzed. Next, a high concentration of the test chemical is placed adjacent to the bacterial solution, and allowed to diffuse into it. If the bacteria respond chemotactically, they form either zones of concentrated bacteria or regions of clearing. One widely-used chemotaxis assay is the quantitative capillary assay in which the test chemical is placed in a narrow-bore capillary, and the bacteria are in a surrounding solution [1]. In this assay, chemotactic responses are measured by determining the number of bacteria that move into the capillary. This assay works well for attractants, but not well for repellents as noted by Tso and Adler [2]. These authors first proposed the chemical-in-plug assay, which is now often called the plug-in-pond assay, as a way of studying the effect of repellent stimuli on bacterial behavior. This quick and simple assay places a potential chemoeffector in an agar plug and surrounds the plug with a turbid suspension of bacteria in soft agar. Because the bacteria can swim in

\footnotetext{
* Correspondence: mandywar@usc.edu; ottemann@ucsc.edu

'Department of Microbiology and Environmental Toxicology, UC Santa Cruz, Santa Cruz, 95064, USA

${ }^{2}$ Department of Geography and Environmental Engineering, The Johns Hopkins University, 3400 N Charles St, Baltimore, MD 21218, USA
}

the soft agar, a zone of clearing quickly appears around the hard agar plug if the chemical within the plug is a repellent. In their assays, Tso and Adler observed a ring of motile bacteria surrounding the outer edge of the cleared zone and showed that the distance this ring had moved away from the plug was dependent on the concentration of the repellent. A variation on the assay, which places potential attractant chemicals within the hard agar plug, has also been used extensively, again because the assay is technically simple and results can be obtained rapidly. The original study by Tso and Adler used Escherichia coli as the model organism, and the assay has since been used to study behavioral responses in an extensive range of bacteria including Bdellovibrio bacteriovorus [3], Campylobacter jejuni [4,5], Shewanella oneidensis [6], Halobacterium salinarum [7], Geobacter metallireducens [8], and Flavimonas oryzihabitans [9]. In the course of our own studies using two completely unrelated bacteria, Helicobacter pylori and Shewanella oneidensis, we found that nonmotile and non-chemotactic mutants form what appear to be chemotactic responses. The usual negative control for these experiments is to note accumulation around a plug lacking any chemical. Here we present evidence that non-motile or non-chemotactic mutants must be used as additional controls to prevent inaccurate conclusions. Several of the above cited studies employed multiple chemotaxis assays, ensuring that conclusions were 
not based on the results of a single assay. We thus are not calling into question the results of previous studies, but are simply pointing out that misinterpretation of results can be prevented by the judicial use of nonmotile or non-chemotactic mutants as negative controls.

\section{Methods}

The H. pylori chemical-in-plug assays were done with wild-type $H$. pylori G27 [10] and SS1 [11] and their isogenic mutants. These strains were grown as described [12] in Brucella broth plus $10 \%$ fetal bovine serum (FBS), a medium called BB10. After growth, the bacteria were collected by low-speed centrifugation, washed and resuspended in a solution of phosphate-buffered saline with $1 \%$ dialyzed FBS (PBS1) and warm $0.3 \%$ Bacto agar. The final bacterial concentration was $\sim 6 \times 10^{7}$ bacteria/ $\mathrm{ml}$. This bacterial solution was poured around hard agar plugs composed of PBS1, 2\% Bacto agar, and the compound to test. After solidifying, the plates were incubated at $37^{\circ} \mathrm{C}$ in $10 \% \mathrm{CO}_{2} / 5 \% \mathrm{O}_{2} / 85 \% \mathrm{~N}_{2}$. Plates were monitored every 30 minutes for up to four hours. Plates were then placed at $4^{\circ} \mathrm{C}$ for up to 24 hours until images were captured using a digital camera. There was no change in the appearance of the plates during the $4^{\circ} \mathrm{C}$ incubation. The doubling time of $H$. pylori is $6-12$ hours, so growth inhibitors were not used for these assays.

For S. oneidensis chemical-in-plug assays, strains were grown aerobically overnight in Luria-Bertani (LB) medium at $30^{\circ} \mathrm{C}$, with shaking. Attractants $(20 \mathrm{mM}$ final concentration) were added to molten $1.5 \%$ agarose prior to the agarose being poured into Petri dishes. The agarose plates were transferred to an anaerobic chamber (atmosphere $5 \% \mathrm{H}_{2}, 95 \% \mathrm{~N}_{2}$ ) to equilibrate overnight. Plugs were then cut from this agarose for the assay. Two methods were used to prepare the S. oneidensis cells, although in both cases approximately $1 \times 10^{10}$ cells $/ \mathrm{ml}$ were used in the assays. In the first method, the overnight LB-grown cultures of $S$. oneidensis were mixed at a $1: 1$ ratio with $1 \%$ molten Bacto agar at $50^{\circ} \mathrm{C}$, chloramphenicol added to a final concentration of 3.4 $\mu \mathrm{g} / \mathrm{ml}$ (to act as a growth inhibitor), and the soft agar containing the cells poured around the equilibrated plugs. In the second method, cells grown overnight in LB were washed with $100 \mathrm{mM}$ HEPES buffer (pH 7.4) to ensure that residual LB medium would not interfere with the assay, then resuspended in fresh $100 \mathrm{mM}$ HEPES (pH 7.4) containing chloramphenicol (as above). The washed and resuspended cells were mixed with $1 \%$ molten agar and poured around the hard agarose plugs. The redox indicator dye resazurin was added to duplicate sets of plates to ensure that no oxygen contamination was present prior to the initiation of the assays.
Responses were observed and documented after 4 hours. Swim plate assays were performed as outlined in [13].

\section{Results and Discussion}

Helicobacter pylori is a human gastric pathogen that requires motility and chemotaxis for infection $[12,14,15]$. There is a limited understanding of what this bacterium uses chemotaxis for; to date, few specific chemicals and properties such as $\mathrm{pH}$ or energy status have been determined $[16,17]$. We thus tried the chemicalin-plug assay to analyze a putative attractant, alanine, which is also required for H. pylori growth [18]. After four hours, zones of clearing were apparent around alanine-containing plugs as well as plugs with diluted growth media (Figure 1). H. pylori exhibits chemotaxis in soft-agar plates containing the same growth media [for example, [19]]. No clearing was seen around the negative control plugs that contained only PBS1+Bacto Agar. The clearing response could first be seen after two hours, and the clearing zone increased throughout the duration of the assay. Additionally, the degree of the response was concentration dependent, with larger clearing zones at high alanine concentrations (Figure 1). We saw similar responses with two $H$. pylori strains, SS1 and G27 (data not shown), and thus proposed initially that this bacterium responds chemotactically to alanine. The zone of clearing observed around plugs containing alanine, or Brucella broth, is reminiscent of a repellent response, as the $H$. pylori leave the vicinity of the alanine, although no ring of cells was observed at the edge of the clearing zone.

Both chemotaxis and motility are required to form chemotactic responses, so we tested $H$. pylori mutants defective for these processes in our assay. The nonmotile $H$. pylori mutant used has the $\operatorname{mot} B$ gene deleted. The MotB protein is a motor protein required for flagellar rotation; mutants lacking it are flagellated but the flagella cannot turn. This mutant has been well characterized [12] and does not recover motility. This mutant, surprisingly, formed the same clearing zones as wildtype H. pylori (Figure 1). To further substantiate this finding, we repeated the assay with multiple characterized non-chemotactic and non-motile mutants generated in two strain backgrounds, G27 and SS1, including cheW, cheA and cheY mutants [20], and found consistent zones of clearing in all strains tested (data not shown). These findings suggest that the zones of clearing are independent of chemotaxis and motility.

These findings with $H$. pylori prompted us to examine whether other bacteria might similarly display false-positive responses in the chemical-in-plug assay. Previously, chemical-in-plug and swim plate assays had been done using S. oneidensis strain MR-1, with the finding that this 

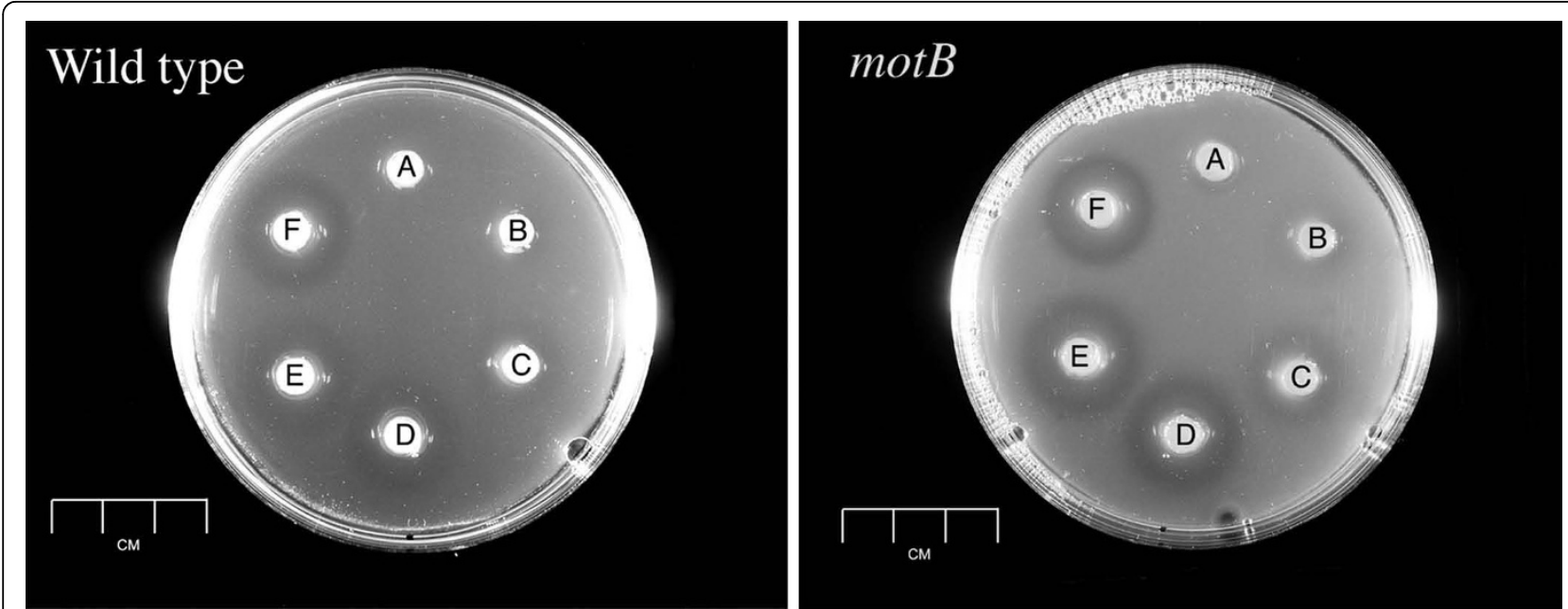

Figure 1 Chemical-in-plug assays with $\boldsymbol{H}$. pylori wild type G27 (left) and SS1 $\Delta$ motB. The topmost "A" plug contains no addition (negative control). Proceeding clockwise the plugs contain $1 \mathrm{mM}$ alanine (B), $10 \mathrm{mM}$ alanine (C), $50 \mathrm{mM}$ alanine (D), $100 \mathrm{mM}$ alanine (E), and a 1:4 dilution of Brucella broth (F). The assay was repeated six independent times; the plates above show one representative assay. Similar results were obtained with wild-type SS1 and non-chemotactic mutants of both SS1 and G27 (data not shown).

microbe responds chemotactically to a number of anaerobic electron acceptors $[6,21,22]$. Subsequently, the genomic sequence of $S$. oneidensis strain MR-1 allowed us to construct and characterize an isogenic nonchemotactic mutant lacking the chemotaxis kinase CheA ( $\triangle$ cheA-3) [13]. This mutant retains wild-type swimming speed, but is unable to reverse direction. The mutant also does not show chemotaxis to anaerobic electron acceptors in either the swim plate or capillary assays [13]. However, no report on the behavior of this mutant in the chemical-in-plug assays was previously made.
In this study, we report that both $S$. oneidensis MR-1 and the $\Delta c h e A-3$ mutant show zones of accumulation around all of the plugs containing anaerobic electron acceptors, but not around the control plugs, in the chemical-in-plug assay. Specifically, nitrate, nitrite, and DMSO (Figure 2), plus TMAO and fumarate (not shown) elicited responses from both wild type and the $\Delta$ cheA-3 mutant. Responses were stronger for the unwashed cells (not shown), although the cells washed and resuspended in $100 \mathrm{mM}$ HEPES still displayed zones of apparent cell accumulation (Figure 2), although

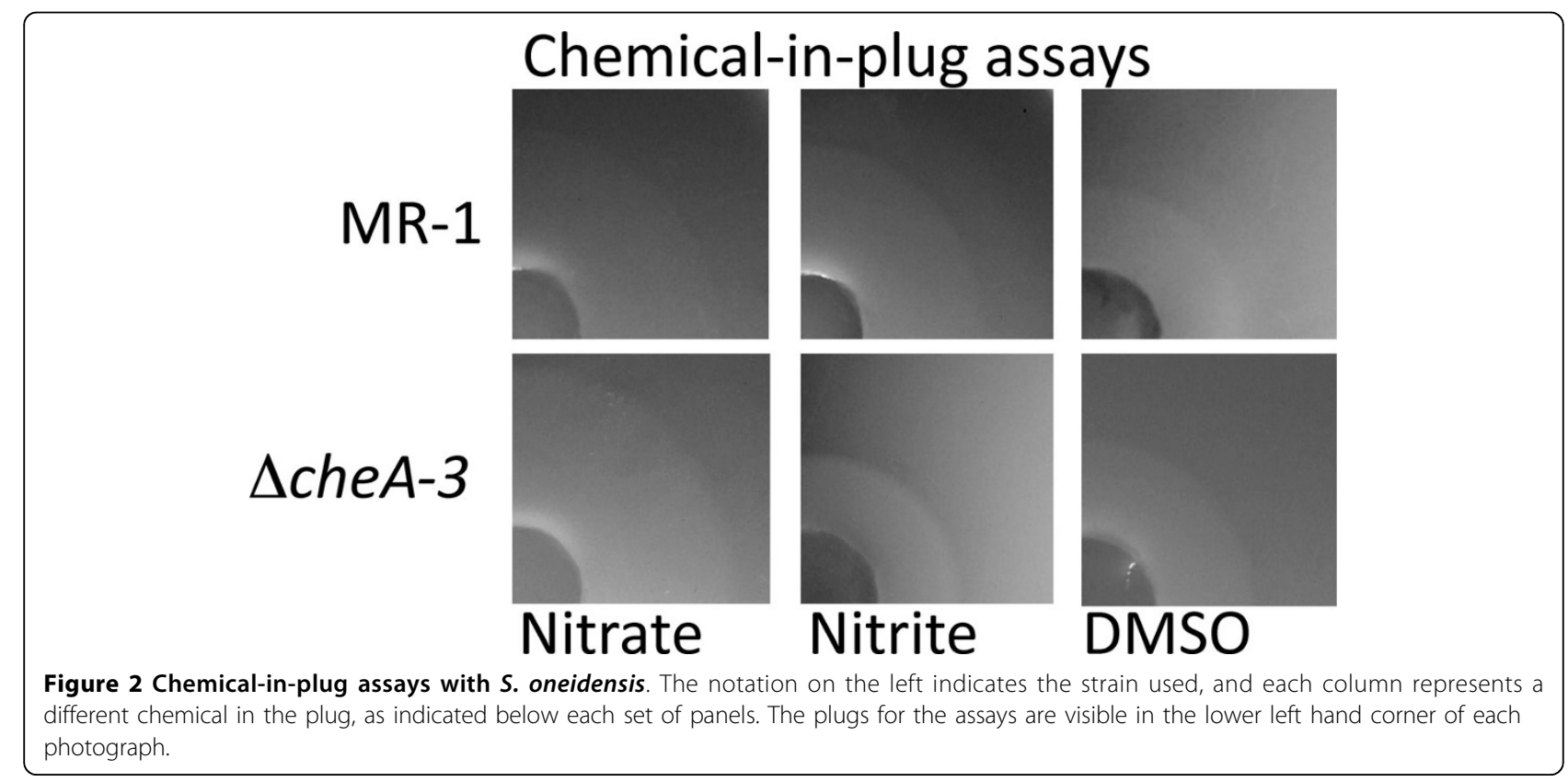


in neither were rings of cells apparent at the edge of the accumulation zones. We confirmed that the $\Delta$ cheA-3 mutant had not reverted to wild-type by performing swim plate assays. As shown previously, the $\Delta$ cheA-3 mutant was unable to respond to electron acceptors in this assay [13]. Because cells that are unable to reverse their direction of swimming would be expected to be non-chemotactic, the results of the swim plate and capillary assays performed previously with the $\Delta$ cheA-3 mutant [13] are more likely to be correct than the results of the chemical-in-plug assays. Consequently, it appears likely that the chemical-in-plug assay generates false positive results when used for analyzing S. oneidensis motility behavior.

\section{Conclusions}

In summary, our analyses show that both non-motile and non-chemotactic mutants can display what appears to be chemotaxis in the chemical-in-plug assay. We observed these motility-independent responses in two unrelated microbes, $H$. pylori and $S$. oneidensis, suggesting it is a common phenomenon in response to several compounds. While both microbes displayed motilityindependent responses, the characteristics of each were different. S. oneidensis had what appeared to be bacterial accumulation around the plugs. A close observation of these zones, however, found them to be white in color rather than the more typical pinkish color of this bacterium. Consequently, it seems possible that the bacteria respond to the chemical gradients emanating from the plugs by forming a precipitate that can be confused with a behavioral response. The recent study by Baraquet et al. [23] suggests that the formation of this precipitate, if that is what it is, is dependent on respiration because mutants unable to respire anaerobically did not show accumulation when anaerobic electron acceptors were used as the attractants. The H. pylori response, in contrast, consists of actual clearing around the plugs. It is possible that the clear zones arise from bacterial lysis, although this seems unlikely given the rather mild nature of some of the plug contents (e.g. 1/4 Brucella broth). The lack of rings of cells at the edges of the zones of clearing and accumulation may be an indicator of a false chemotactic response. However, we did not explore the basis for this response further.

Choosing appropriate chemotaxis assays for studies involving different microorganisms is complex. For example, H. pylori has displayed chemotaxis in a liquidbased microscopic assay [16], in commercial chemotaxis chambers [17] and in the agarose-in-plug bridge assay [T. M. Andermann and K. M. Ottemann, unpublished and [24]]. Some scientists have also reported success with $H$. pylori capillary assays $[25,26]$, but our own experience has found this assay to be unreliable (unpublished). For S. oneidensis, the swim plate and capillary assays seem reliable, as does a microscopic version of the chemical-in-plug assay where bands of motile cells in liquid have been filmed moving towards or away from plugs containing chemoeffectors (unpublished). However, our conclusion is that the chemicalin-plug assay should only be employed, in combination with other assays, if suitable non-chemotactic or nonmotile mutants are available to act as negative controls.

\section{Acknowledgements}

This work was funded by a Burroughs Wellcome Career Award to KMO MJW was supported by the Office of Science (BER), U.S. Department of Energy, Grant No. DE-FG02-07ER64387, via the Shewanella Federation consortium.

\section{Author details}

'Department of Microbiology and Environmental Toxicology, UC Santa Cruz, Santa Cruz, 95064, USA. ²Department of Geography and Environmental Engineering, The Johns Hopkins University, 3400 N Charles St, Baltimore, MD 21218, USA. ${ }^{3}$ Department of Earth Sciences, 3651 Trousdale Pkwy, Los Angeles, CA 90089, USA.

\section{Authors' contributions}

JI, ACG, MJW and KMO designed the experiments and interpreted the data. $\mathrm{J}$ and ACG performed the experiments. MJW and KMO wrote the manuscript. All authors read and approved the final manuscript.

\section{Competing interests}

The authors declare that they have no competing interests.

Received: 16 February 2010 Accepted: 16 March 2010

Published: 16 March 2010

\section{References}

1. Adler J: A method for measuring chemotaxis and use of the method to determine optimum conditions for chemotaxis by Escherichia coli. Journal of General Microbiology 1973, 74(1):77-91.

2. Tso WW, Adler J: Negative chemotaxis in Escherichia coli. Journal of bacteriology 1974, 118:560-576.

3. Straley SC, LaMarre AG, Lawrence $L$, Conti SF: Chemotaxis of Bdellovibrio bacteriovorus toward pure compounds. Journal of bacteriology 1979, 140(2):634-642.

4. Hugdahl MB, Beery JT, Doyle MP: Chemotactic behavior of Campylobacter jejuni. Infection and immunity 1988, 56(6):1560-1566.

5. Quinones B, Miller WG, Bates AH, Mandrell RE: Autoinducer-2 production in Campylobacter jejuni contributes to chicken colonization. Applied and environmental microbiology 2009, 75(1):281-285.

6. Bencharit $\mathrm{S}$, Ward MJ: Chemotactic responses to metals and anaerobic electron acceptors in Shewanella oneidensis MR-1. Journal of bacteriology 2005, 187(14):5049-5053.

7. Kokoeva MV, Oesterhelt D: BasT, a membrane-bound transducer protein for amino acid detection in Halobacterium salinarum. Molecular microbiology 2000, 35(3):647-656.

8. Childers SE, Ciufo S, Lovley DR: Geobacter metallireducens accesses insoluble Fe(III) oxide by chemotaxis. Nature 2002, 416(6882):767-769.

9. Lanfranconi MP, Alvarez HM, Studdert CA: A strain isolated from gas oilcontaminated soil displays chemotaxis towards gas oil and hexadecane. Environmental microbiology 2003, 5(10):1002-1008.

10. Censini S, Lange C, Xiang Z, Crabtree JE, Ghiara P, Borodovsky M, Rappuoli R, Covacci A: cag, a pathogenicity island of Helicobacter pylori, encodes type I-specific and disease-associated virulence factors. Proceedings of the National Academy of Sciences of the United States of America 1996, 93(25):14648-14653.

11. Lee A, O'Rourke J, De Ungria MC, Robertson B, Daskalopoulos G, Dixon MF: A standardized mouse model of Helicobacter pylori infection: Introducing the Sydney strain. Gastroenterology 1997, 112(4):1386-1397. 
12. Ottemann KM, Lowenthal A: Helicobacter pylori uses motility for both initial colonization and to attain robust infection. Infection and immunity 2002, 70:1984-1990.

13. Li J, Romine MF, Ward MJ: Identification and analysis of a highly conserved chemotaxis gene cluster in Shewanella species. FEMS Microbiology Letters 2007, 273(2):180-186.

14. Eaton KA, Suerbaum S, Josenhans C, Krakowka S: Colonization of gnotobiotic piglets by Helicobacter pylori deficient in two flagellin genes. Infection and immunity 1996, 64(7):2445-2448.

15. Foynes S, Dorrell N, Ward SJ, Stabler RA, McColm AA, Rycroft AN, Wren BW: Helicobacter pylori possesses two CheY response regulators and a histidine kinase sensor, CheA, which are essential for chemotaxis and colonization of the gastric mucosa. Infection and immunity 2000, 68(4):2016-2023.

16. Croxen MA, Sisson G, Melano R, Hoffman PS: The Helicobacter pylori Chemotaxis Receptor TlpB (HP0103) Is Required for pH Taxis and for Colonization of the Gastric Mucosa. Journal of bacteriology 2006, 188(7):2656-2665.

17. Schweinitzer T, Mizote T, Ishikawa N, Dudnik A, Inatsu S, Schreiber S, Suerbaum S, Aizawa SI, Josenhans C: Functional characterization and mutagenesis of the proposed behavioral sensor TlpD of Helicobacter pylori. Journal of bacteriology 2008, 190(9):3244-3255.

18. Testerman TL, Conn PB, Mobley HL, McGee DJ: Nutritional requirements and antibiotic resistance patterns of Helicobacter species in chemically defined media. Journal of Clinical Microbiology 2006, 44(5):1650-1658.

19. McGee DJ, Langford ML, Watson EL, Carter JE, Chen Y-T, Ottemann KM: Colonization and inflammation deficiencies in Mongolian gerbils infected by Helicobacter pylori chemotaxis mutants. Infection and immunity 2005, 73:1820-1827.

20. Terry K, Williams SM, Connolly L, Ottemann KM: Chemotaxis plays multiple roles in Helicobacter pylori animal infection. Infection and immunity 2005, 73:803-811.

21. Nealson KH, Moser DP, Saffarini DA: Anaerobic electron acceptor chemotaxis in Shewanella putrefaciens. Applied and environmental microbiology 1995, 61(4):1551-1554.

22. Myers $\mathrm{CR}$, Nealson $\mathrm{KH}$ : Bacterial Manganese Reduction and Growth with Manganese Oxide as the Sole Electron Acceptor. Science 1988, 240(4857):1319-1321.

23. Baraquet C, Theraulaz L, lobbi-Nivol C, Mejean V, Jourlin-Castelli C: Unexpected chemoreceptors mediate energy taxis towards electron acceptors in Shewanella oneidensis. Molecular microbiology 2009, 73(2):278-290.

24. Yu HS, Alam M: An agarose-in-plug bridge method to study chemotaxis in the Archaeon Halobacterium salinarum. FEMS Microbiology Letters 1997, 156(2):265-269.

25. Mizote T, Yoshiyama H, Nakazawa T: Urease-independent chemotactic responses of Helicobacter pylori to urea, urease inhibitors, and sodium bicarbonate. Infection and immunity 1997, 65(4):1519-1521.

26. Cerda O, Rivas A, Toldeo H: Helicobacter pylori strain ATCC700392 encodes a methyl-accepting chemotaxis receptor protein (MCP) for arginine and sodium bicarbonate. FEMS Microbiology Letters 2003, 224(2):175-181.

doi:10.1186/1756-0500-3-77

Cite this article as: Li et al:: The chemical-in-plug bacterial chemotaxis assay is prone to false positive responses. BMC Research Notes 2010 3:77.

\section{Submit your next manuscript to BioMed Central and take full advantage of:}

- Convenient online submission

- Thorough peer review

- No space constraints or color figure charges

- Immediate publication on acceptance

- Inclusion in PubMed, CAS, Scopus and Google Scholar

- Research which is freely available for redistribution 